Research Article

\title{
The Effect of Achyranthes aspera Extracts on Mild Steel Corrosion in Industrial Water Medium
}

\author{
Chikkur B. Pradeep Kumar and Kikkeri N. Mohana \\ Department of Studies in Chemistry, University of Mysore, Manasagangotri, Mysore 570006, India
}

Correspondence should be addressed to Kikkeri N. Mohana; drknmohana@gmail.com

Received 24 March 2013; Accepted 9 May 2013

Academic Editors: O. Benali, C. V. D’Alkaine, A. Y. El-Etre, A. Hermann, R. Salghi, and E. Stupnisek-Lisac

Copyright ( 2013 C. B. P. Kumar and K. N. Mohana. This is an open access article distributed under the Creative Commons Attribution License, which permits unrestricted use, distribution, and reproduction in any medium, provided the original work is properly cited.

\begin{abstract}
Achyranthes aspera (AA) extracts were studied as corrosion inhibitor for mild steel (MS) in industrial water medium using mass loss and electrochemical techniques. The results of the study revealed that AA extracts inhibit MS corrosion through adsorption process following Langmuir adsorption isotherm model. The protection efficiency increased with increase in inhibitor concentration and decreased with temperature. The electrochemical impedance spectroscopy (EIS) measurements showed that the charge transfer resistance increases with increase in the concentration of AA extracts. The polarization curves obtained indicate that AA extracts act as mixed type of inhibitor. Scanning electron microscopy (SEM) was used to analyze the surface adsorbed film.
\end{abstract}

\section{Introduction}

The use of inhibitors is one of the most practical methods for protection against corrosion and prevention of unexpected metal dissolution. Different organic and inorganic compounds have been studied as inhibitors to protect metals from corrosive attack. The efficiency of these organic corrosion inhibitors is related to the presence of polar functional groups with $\mathrm{S}, \mathrm{O}$, and $\mathrm{N}$ atoms in the molecule [1-5]. Such compounds can adsorb onto the metal surface and block the active surface sites, thus reducing the corrosion rate. Nevertheless, most of these compounds are not only expensive but also toxic for living beings. So, plant extracts have attracted the attention of researchers as ecofriendly corrosion inhibitors for many decades [69]. Plant extracts are an incredibly rich source of natural chemical compounds that can be extracted by simple procedures with low cost and are biodegradable in nature. The actual inhibitors in the plant extracts are usually alkaloids and other organic nitrogen bases, as well as carbohydrates, proteins, and their acid hydrolysis products [10]. Alkaloids have an ability to coordinate the transition metals or their alloys via the d-orbitals of metal and empty p-orbitals of the heteroatoms in the inhibitor molecules. A number of natural compounds have been used as corrosion inhibitors for metals and their alloys in acidic, alkaline, and neutral solutions [11-15].

Achyranthes aspera (AA) is one of the most important antioxidant medicinal plants, and it is an excellent source of several flavonoids, tannins, reducing sugars, alkaloids, and saponins [16]. Besides these phytoconstituents, several glycosides [17], fatty acids [18], ecdysterone [19], and triterpenoids [20] were isolated in various parts of plant. In the light of phytoconstituents reported, the present study was intended to ascertain the ability of methanolic extracts of AA to protect the mild steel in industrial water medium. Effects of inhibitor concentration, temperature, and immersion time on the corrosion rate were investigated and discussed. Gravimetric, potentiodynamic polarization, and electrochemical impedance spectroscopy (EIS) techniques were employed to study the mechanism of corrosion inhibition. Adsorption behaviour and thermodynamic parameters were obtained to establish the mechanism of adsorption. The morphology of the inhibited mild steel was analyzed using scanning electron microscopic images.

\section{Experimental}

2.1. Preparation of Plant Extracts. Healthy, disease free, mature leaves of Achyranthes aspera (AA) collected from 
Western Ghats, Karnataka, India, were used for the preparation of methanolic extracts. Thoroughly washed mature leaves were shade dried and then powdered with the help of a blender. The powder was extracted with methanol using a Soxhelt extractor. The extracts were concentrated using rotary flash evaporator and preserved at $\pm 5^{\circ} \mathrm{C}$ in airtight bottle until further use.

2.2. Materials. The specimens used for corrosion tests were mild steel (MS) coupons which have the following composition (wt \%): $0.051 \mathrm{C}: 0.023 \mathrm{Si}: 0.005 \mathrm{P}$ : $0.103 \mathrm{Al}: 0.179 \mathrm{Mn}$ : $0.023 \mathrm{~S}$ and the remainder iron. The test solution was industrial water collected from heat exchangers and reboilers of the chemical industries in and around Mysore city, India. The chemical composition of the industrial water (ppm) obtained from ionic chromatograph was $7500 \mathrm{Cl}^{-} ; 64 \mathrm{Ca}^{2+}$; $3440 \mathrm{SO}_{4}{ }^{2-} ; 23 \mathrm{Mg}^{2+} ; 140 \mathrm{Na}^{+} ; 0.28 \mathrm{PO}_{4}{ }^{3-}$. Prior to gravimetric and electrochemical measurements, the surface of the specimens was polished under running tap water using emery paper (SiC, grade 220-600), rinsed with distilled water, dried on a clean tissue paper, immersed in benzene for $5 \mathrm{~s}$, dried and immersed in acetone for $5 \mathrm{~s}$, and dried with clean tissue paper. Finally, the specimens were kept in desiccators until use. At the end of the gravimetric experiment, the specimens were carefully washed with acetone and benzene, dried, and then weighed. For polarization and electrochemical impedance studies, the MS specimen was embedded in epoxy resin to expose a geometrical surface area of $1 \mathrm{~cm}^{2}$ to the electrolyte.

\subsection{Methods}

2.3.1. Gravimetric Measurements. Gravimetric experiments were carried out in a glass cell, and the solution volume was $100 \mathrm{~cm}^{3}$. The temperature of the environment was maintained by thermostatically controlled water bath (Weiber, India) with an accuracy of $\pm 0.2^{\circ} \mathrm{C}$ under aerated condition. The mild steel specimens used were rectangular with a dimension of $1 \mathrm{~cm} \times 1 \mathrm{~cm} \times 0.1 \mathrm{~cm}$. The initial weight of the specimen was recorded using an analytical balance (precision $\pm 0.1 \mathrm{mg}$ ). After the corrosion test in industrial water with and without inhibitor, the specimens were carefully washed in double distilled water, dried, and then weighed. The weight loss of the specimen was determined after an immersion period of 10 to $50 \mathrm{~h}$ at the temperature range of 30 to $60^{\circ} \mathrm{C}$. Triplicate experiments were performed in each case, and the average mass loss was reported. The corrosion rate (CR) and inhibition efficiency (\% IE) are calculated using

$$
\begin{gathered}
\mathrm{CR}=\frac{\Delta W}{S t}, \\
\mathrm{IE} \%=\frac{(\mathrm{CR})_{a}-(\mathrm{CR})_{p}}{(\mathrm{CR})_{a}} \times 100,
\end{gathered}
$$

where $\Delta W$ is the weight loss, $S$ is the surface area of the specimen $\left(\mathrm{cm}^{2}\right), t$ is the immersion time $(h)$, and $(\mathrm{CR})_{a}$, $(\mathrm{CR})_{p}$ are corrosion rates in the absence and presence of the inhibitor, respectively.

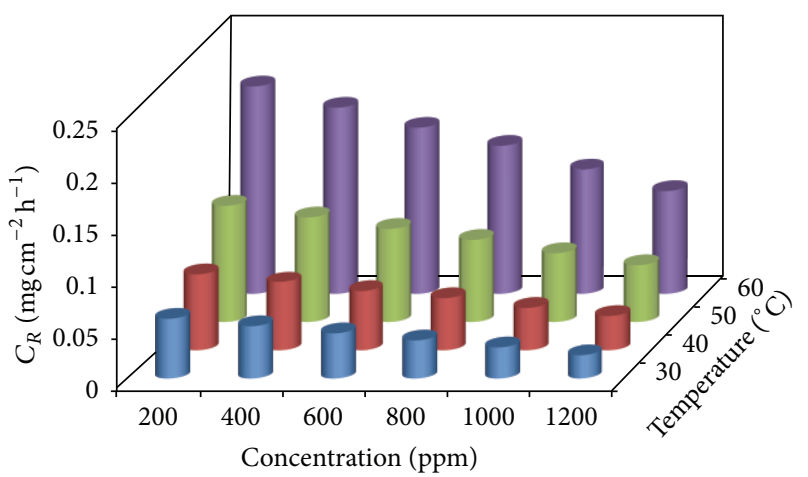

FIGURE 1: Variation of inhibition efficiency with temperature and inhibitor concentration in the absence and presence of different concentrations of AA extracts.

2.3.2. Electrochemical Measurements. Electrochemical tests were carried out with a $\mathrm{CH}$-analyzer model $\mathrm{CH} 1660 \mathrm{D}$. The cell arrangement used was a conventional three-electrode cell with platinum counter electrode, saturated calomel electrode as reference electrode, and test material (mild steel) as working electrode. Anodic and cathodic polarization curves were recorded in the potential range from -350 to $-800 \mathrm{mV}$ with a scan rate of $0.4 \mathrm{mV} \mathrm{s}^{-1}$. The $\mathrm{AC}$ impedance measurements were performed in the frequency range from $10 \mathrm{kHz}$ to $0.05 \mathrm{~Hz}$ with signal amplitude of $\pm 10 \mathrm{mV}$.

2.3.3. Morphological Investigation. The surface morphology of the mild steel samples in the absence and presence of AA extracts (1200 ppm in industrial water) at $30^{\circ} \mathrm{C}$ was investigated by scanning electron microscopy (SEM) technique (Model JSM-5800).

\section{Results and Discussion}

3.1. Mass Loss Studies. Weight loss of MS was determined in industrial water medium in the absence and presence of different concentrations of AA extracts. The inhibition efficiency of MS with and without the addition of different concentrations of AA extracts was determined after $40 \mathrm{~h}$ at different temperature, and the results are depicted in Table 1. It has been observed that 1200 ppm of AA extracts serve as an optimum concentration that exhibit higher inhibition efficiency. The corrosion rate of MS decreased on increasing the inhibitor concentration up to $1200 \mathrm{ppm}$. This behavior could be attributed to the increase in adsorption of the inhibitor at the metal/solution interface [21] and reduces the surface area that is available for direct attack on the metal surface. Above $1200 \mathrm{ppm}$, the corrosion rate approximately remained constant. The constant rate obtained could be attributed to the competitive adsorption effect between inhibitor molecules and the metal surface which is already covered with initial layers of molecules [22]. The \% IE at different concentrations of AA extracts decreases with increasing temperature from $303 \mathrm{~K}$ to $333 \mathrm{~K}$ (Figure 1 ). This is due to increased rate of dissolution process of MS and partial desorption of the inhibitor from the metal surface with temperature [23]. 
TABLE 1: $C_{R}$ and IE (\%) obtained from weight loss measurements of MS in industrial water medium containing various concentrations of AA extracts at different temperatures.

\begin{tabular}{|c|c|c|c|c|c|c|c|c|}
\hline \multirow{3}{*}{$C(\mathrm{ppm})$} & \multicolumn{8}{|c|}{ Temperature } \\
\hline & \multicolumn{2}{|c|}{$30^{\circ} \mathrm{C}$} & \multicolumn{2}{|c|}{$40^{\circ} \mathrm{C}$} & \multicolumn{2}{|c|}{$50^{\circ} \mathrm{C}$} & \multicolumn{2}{|c|}{$60^{\circ} \mathrm{C}$} \\
\hline & $C_{R}\left(\mathrm{mg} \mathrm{cm}^{-2} \mathrm{~h}^{-1}\right)$ & IE \% & $C_{R}\left(\mathrm{mg} \mathrm{cm}^{-2} \mathrm{~h}^{-1}\right)$ & IE \% & $C_{R}\left(\mathrm{mg} \mathrm{cm}^{-2} \mathrm{~h}^{-1}\right)$ & IE \% & $C_{R}\left(\mathrm{mg} \mathrm{cm}^{-2} \mathrm{~h}^{-1}\right)$ & IE \% \\
\hline 0 & 0.1204 & - & 01428 & - & 0.2048 & - & 0.3326 & - \\
\hline 200 & 0.0573 & 52.40 & 0.0736 & 48.48 & 0.1122 & 44.04 & 0.2001 & 39.84 \\
\hline 400 & 0.0501 & 58.38 & 0.0656 & 54.08 & 0.1011 & 50.63 & 0.1795 & 46.09 \\
\hline 600 & 0.0433 & 64.03 & 0.0568 & 60.24 & 0.0901 & 56.00 & 0.1601 & 51.87 \\
\hline 800 & 0.0365 & 69.68 & 0.0499 & 65.07 & 0.0795 & 61.18 & 0.1426 & 57.13 \\
\hline 1000 & 0.0298 & 75.24 & 0.0406 & 71.58 & 0.0668 & 67.38 & 0.1201 & 63.89 \\
\hline 1200 & 0.0223 & 81.47 & 0.0328 & 77.04 & 0.0552 & 73.04 & 0.0995 & 70.08 \\
\hline
\end{tabular}

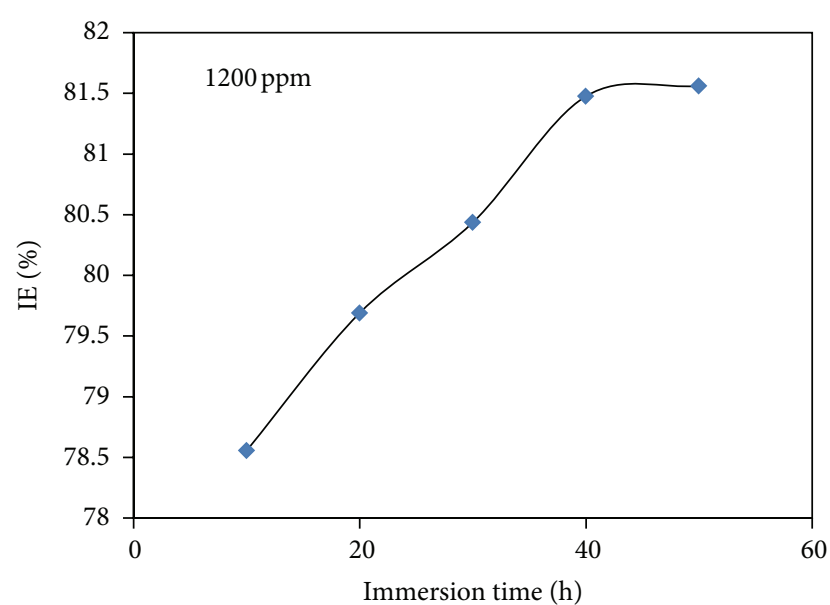

Figure 2: Effect of immersion time on IE \% of AA extracts.

The inhibitive effect of AA extracts is ascribed to the presence of several organic compounds in the extracts. AA extracts are rich in organic compounds of high molecular weight with heteroatoms and $\pi$ centers in their molecular structures. These include several flavonoids, tannins, reducing sugars, alkaloids, saponines, glycosides, fatty acids, ecdysterone, betaine, and triterpenoids. The synergistic and antagonistic effects may play an important role in the inhibition efficiency of AA extracts [24].

3.2. Effect of Immersion Time. In order to assess the stability of the inhibitor on MS surface, weight loss measurements were performed in industrial water medium in the absence and presence of AA extract for 10-50 h of immersion time at 303 K. From Figure 2, it can be observed that the inhibition efficiency of AA extracts increased with immersion time and stabilized after $40 \mathrm{hr}$. This increase in inhibition of AA extracts with immersion time reflects strong adsorption on the mild steel surface resulting in a more protective layer.

3.3. Effect of Temperature. Analysis of temperature dependence of inhibition efficiency and comparison of corrosion activation energies in the absence and presence of AA extracts give some insight into the possible mechanism of inhibitor adsorption. The weight loss measurements were carried out as a function of temperature $\left(30\right.$ to $\left.60^{\circ} \mathrm{C}\right)$ and concentration (200 to $1200 \mathrm{ppm}$ ) at 10 to $50 \mathrm{~h}$ immersion time.

The percentage inhibition efficiencies (IE\%) and corrosion rates (CR) are summarized in Table 1 . It was found that increase in temperature leads to an increase in the corrosion rate in the absence and presence of AA extracts in industrial water medium. The dependence of corrosion rate on temperature can be expressed by the following Arrhenius equation:

$$
\mathrm{CR}=A \exp \left(-\frac{E_{a}^{*}}{R T}\right)
$$

where $E_{a}^{*}$ is the apparent activation energy, $T$ is the absolute temperature, $A$ is the Arrhenius preexponential constant, and $R$ is the universal gas constant. The apparent activation energy and preexponential factor for different concentrations of the inhibitor were calculated from the plots of logarithm of CR versus $1 / T$ (Figure 3 ), and the results are shown in Table 2 . It is clear that the activation energy increases in the presence of AA extracts and consequently corrosion rate decreases. An alternative formulation of Arrhenius equation is [25]

$$
\mathrm{CR}=\frac{R T}{N h} \exp \frac{\Delta S^{*}}{R} \exp \left(-\frac{\Delta H^{*}}{R T}\right)
$$

where $h$ is Planck's constant, $N$ is Avogadro's number, $R$ is the universal gas constant, $\Delta H^{*}$ is the enthalpy of activation, and $\Delta S^{*}$ is the entropy of activation. Using (3), plots of $\log \left(C_{R} / T\right)$ versus $1 / T$ gave straight lines with a slope of $\left(-\Delta H^{*} / 2.303 R\right)$ and an intercept of $\left[\log (R / N h)+\Delta S^{*} / 2.303 R\right]$ (Figure 4) from which the values of $\Delta H^{*}$ and $\Delta S^{*}$ are calculated and tabulated in Table 2. Inspection of Table 2 reveals that the calculated values of $\Delta S^{*}$ for AA extracts in industrial water medium are large and negative. The entropy of activation values are less negative for inhibited solutions than that for the uninhibited solutions. This suggests that an increase in randomness occurred while moving from reactants to the activated complex [26]. The positive sign of $\Delta H^{*}$ reflects the endothermic nature of the MS dissolution process, suggesting that the dissolution of MS is slow in the presence of inhibitor 


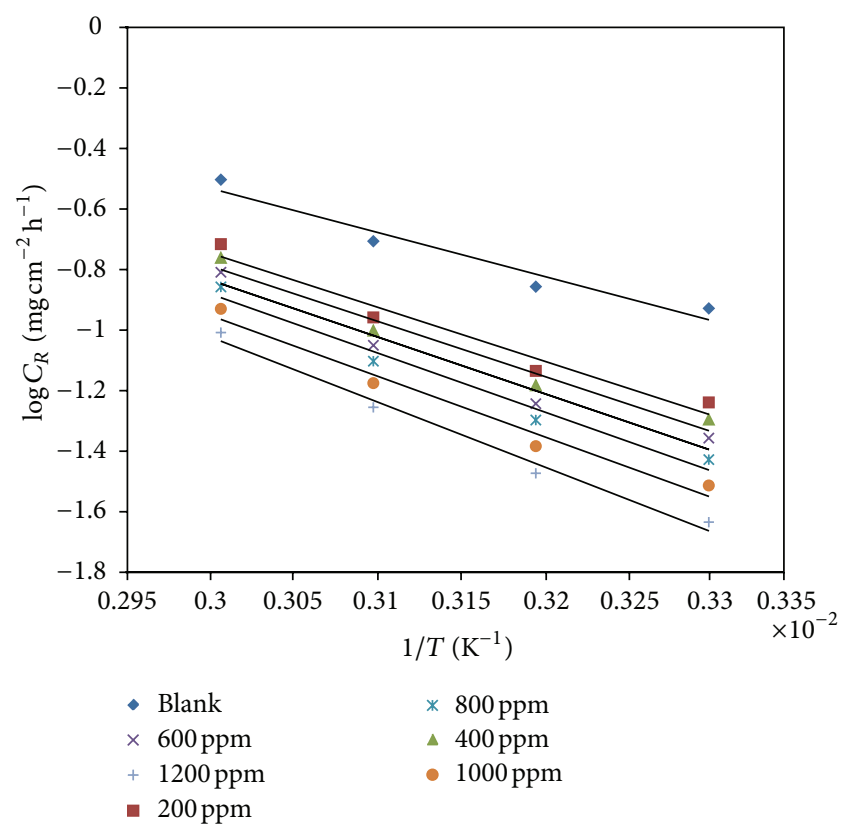

FIGURE 3: Arrhenius plots for MS in industrial water medium in the absence and presence of different concentrations of AA extracts.

[27]. The values of $\Delta H^{*}$ could also be obtained from the following equation:

$$
\Delta H^{*}=E_{a}^{*}-R T .
$$

The values of $\Delta H^{*}$ obtained here are in very good agreement with those obtained from (3), confirming the endothermic process of mild steel dissolution in industrial water medium.

3.4. Adsorption Isotherm. The surface coverage $(\theta)$ of corrosion inhibitor on MS is the most useful parameter for the study of the adsorption behaviour of the inhibitor. A direct relationship between inhibition efficiency and the degree of surface coverage can be assumed for different concentrations of the inhibitor. Data obtained from mass loss measurements were tested graphically for fitting various isotherms including Langmuir, Frumkin, and Temkin. However, the best fit is obtained from Langmuir isotherm (Figure 5). This isotherm assumes that the adsorbed molecules occupy only one site, and there are no interactions with other adsorbed species [28]. According to this isotherm $\Theta$ is related to inhibitor concentration as

$$
\frac{C}{\theta}=\frac{1}{K_{\mathrm{ads}}}+C
$$

where $K_{\text {ads }}$ is the equilibrium constant for adsorption, $C$ is the concentration of the inhibitor, and $\theta$ is the surface coverage. The strong correlation $\left(R^{2}>0.97\right)$ suggests that the adsorption of inhibitor on the MS surface obeyed this isotherm. The $K_{\text {ads }}$ is related to the free energy of adsorption $\left(\Delta G_{\mathrm{ads}}\right)$ using the following equation:

$$
K_{\mathrm{ads}}=\frac{1}{55.5} \exp \left(\frac{-\Delta G_{\mathrm{ads}}}{R T}\right)
$$

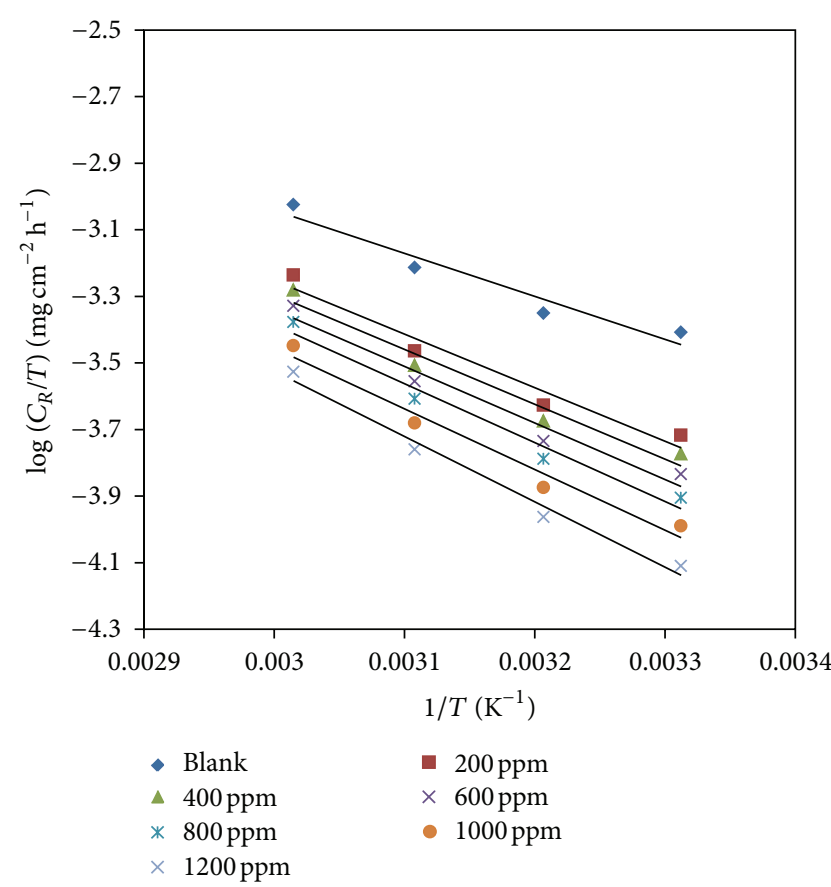

FIgURE 4: Alternative Arrhenius plots for MS in industrial water medium in the absence and presence of different concentrations of AA extracts.

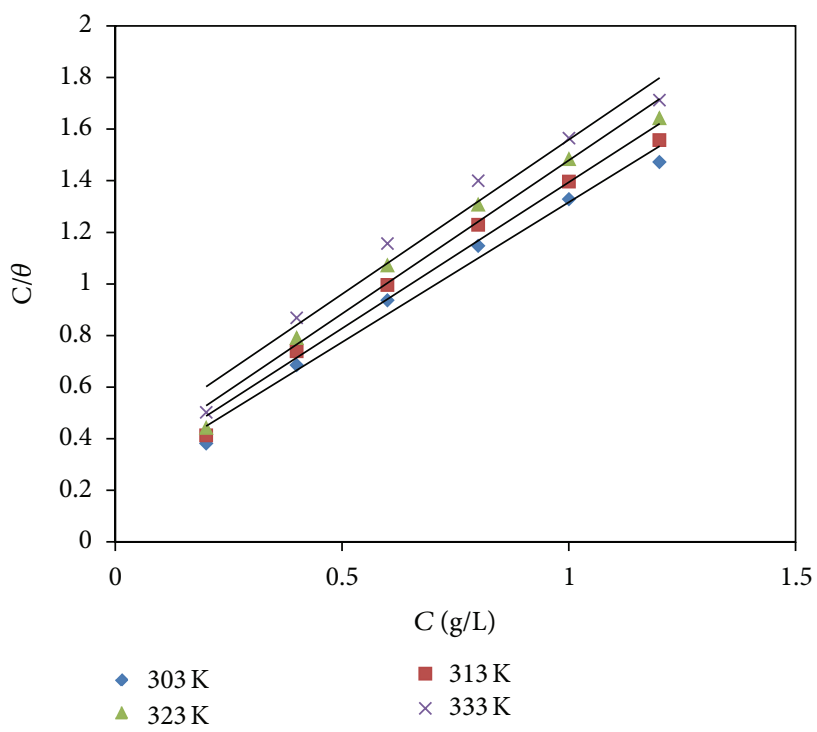

FIGURE 5: Langmuir adsorption isotherm of AA extracts on MS in industrial water medium at different temperatures.

where $R$ is the universal gas constant, $T$ is the absolute temperature, and 55.5 is the concentration of water in solution $\left(\mathrm{mol} \mathrm{L}^{-1}\right)$. The values free energy of adsorption for AA extracts are presented in Table 3. The negative values of $\Delta G_{\text {ads }}$ means that the adsorption of AA on MS surface is a spontaneous process and furthermore shows the strong interaction of the inhibitor onto the MS surface [29]. 
TABLE 2: Activation parameters for MS in industrial water medium in the absence and presence of different concentrations of AA extracts.

\begin{tabular}{lccccc}
\hline$C(\mathrm{ppm})$ & $E_{a}^{*}\left(\mathrm{~kJ} \mathrm{~mol}^{-1}\right)$ & $k\left(\mathrm{mg} \mathrm{cm}^{-2} \mathrm{~h}^{-1}\right)$ & $\Delta H^{*}\left(\mathrm{~kJ} \mathrm{~mol}^{-1}\right)$ & $\left.\Delta H^{*}=E_{a}^{*}-R T(\mathrm{~kJ} \mathrm{~mol})^{-1}\right)$ & $\Delta S^{*}\left(\mathrm{~J} \mathrm{~mol}^{-1} \mathrm{~K}^{-1}\right)$ \\
\hline 0 & 28.41 & 9977.06 & 25.77 & 25.89 & -178.35 \\
200 & 35.34 & 66221.65 & 32.16 & 32.82 & -163.43 \\
400 & 35.47 & 65162.84 & 32.91 & 32.96 & -162.03 \\
600 & 36.66 & 93972.33 & 33.94 & 34.14 & -159.85 \\
800 & 38.84 & 181970.1 & 35.40 & 36.33 & -156.44 \\
1000 & 39.80 & 215774.4 & 36.43 & 37.28 & -154.72 \\
1200 & 40.11 & 179060.6 & 39.23 & 37.59 & -147.77 \\
\hline
\end{tabular}

TABLE 3: Thermodynamic adsorption parameters for adsorption of AA extracts on MS in industrial water medium at different temperatures from Langmuir adsorption isotherm.

\begin{tabular}{|c|c|c|c|c|c|c|}
\hline Temperature $(\mathrm{K})$ & $R^{2}$ & $K_{\mathrm{ads}}\left(\mathrm{Lg}^{-1}\right)$ & $\Delta G_{\text {ads }}\left(\mathrm{kJ} \mathrm{mol}^{-1}\right)$ & $\Delta H_{\mathrm{ads}}\left(\mathrm{kJ} \mathrm{mol}{ }^{-1}\right)$ & $\Delta S_{\text {ads }}\left(\mathrm{J} \mathrm{mol}^{-1} \mathrm{~K}^{-1}\right)$ & $\Delta G_{\mathrm{ads}}=\Delta H_{\mathrm{ads}}-T \Delta S_{\mathrm{ads}}\left(\mathrm{kJ} \mathrm{mol}^{-1}\right)$ \\
\hline 303 & 0.983 & 4310.34 & -31.20 & & & -30.26 \\
\hline 313 & 0.981 & 3816.79 & -31.91 & $\begin{array}{c}-11.98^{\mathrm{a}} \\
-12.11^{\mathrm{b}}\end{array}$ & $\begin{array}{c}63.58^{\mathrm{a}} \\
63^{\mathrm{b}}\end{array}$ & -30.90 \\
\hline 323 & 0.977 & 3448.27 & -32.66 & & & -31.53 \\
\hline 333 & 0.970 & 2762.43 & -33.06 & & & -32.17 \\
\hline
\end{tabular}

${ }^{\mathrm{a}}$ Values obtained from (7). ${ }^{\mathrm{b}}$ Values obtained from (8).

Generally, $\Delta G_{\text {ads }}$ values of the order of $-20 \mathrm{~kJ} \mathrm{~mol}^{-1}$ or higher are associated with an electrostatic interaction between charged molecules and charged metal surface (physisorption), and those of $-40 \mathrm{~kJ} \mathrm{~mol}^{-1}$ or lower indicate charge sharing or a transfer from the inhibitor molecules to the metal surface to form a coordinate covalent bond (chemisorption) [30]. The values for $\Delta G_{\text {ads }}$ for AA extracts on the MS surface are in the ranges of -31.20 to -33.06 ; indicating that the adsorption of AA extracts on MS surface is neither typical physisorption nor typical chemisorption, but it is a complex mixed-type adsorption; that is, it involves both physisorption and chemisorption [31]. The enthalpy and entropy of adsorption $\left(\Delta H_{\text {ads }}\right.$ and $\left.\Delta S_{\text {ads }}\right)$ can be calculated using

$$
\ln K_{\mathrm{ads}}=\ln \frac{1}{55.5}-\frac{\Delta H_{\mathrm{ads}}}{R T}+\frac{\Delta S_{\mathrm{ads}}}{R} .
$$

From (7), the values of $\Delta H_{\text {ads }}$ and $\Delta S_{\text {ads }}$ were evaluated from the slope and intercept of the plot of $\ln K_{\mathrm{ads}}$ versus $1 / T$ (Figure 6). All the calculated thermodynamic parameters are listed in Table 3. It has been found that the values $\Delta H_{\mathrm{ads}}$ are negative, suggesting that the adsorption of the inhibitor is an exothermic process [32]. Adsorption entropy is positive and large indicating that the driving force for the adsorption of adsorbate is the increase in entropy during the process of adsorption rather than the decrease in enthalpy [33].

The values of $\Delta H_{\text {ads }}$ and $\Delta S_{\text {ads }}$ can also be calculated by using following equation:

$$
\Delta G_{\mathrm{ads}}=\Delta H_{\mathrm{ads}}-T \Delta S_{\mathrm{ads}} .
$$

Using (8), the plot of $\Delta G_{\text {ads }}$ versus $T$ gives a straight line (Figure 7) with a slope of $-\Delta S_{\text {ads }}$ and intercept of $\Delta H_{\mathrm{ads}}$. The values obtained are well correlated with those obtained from (7).

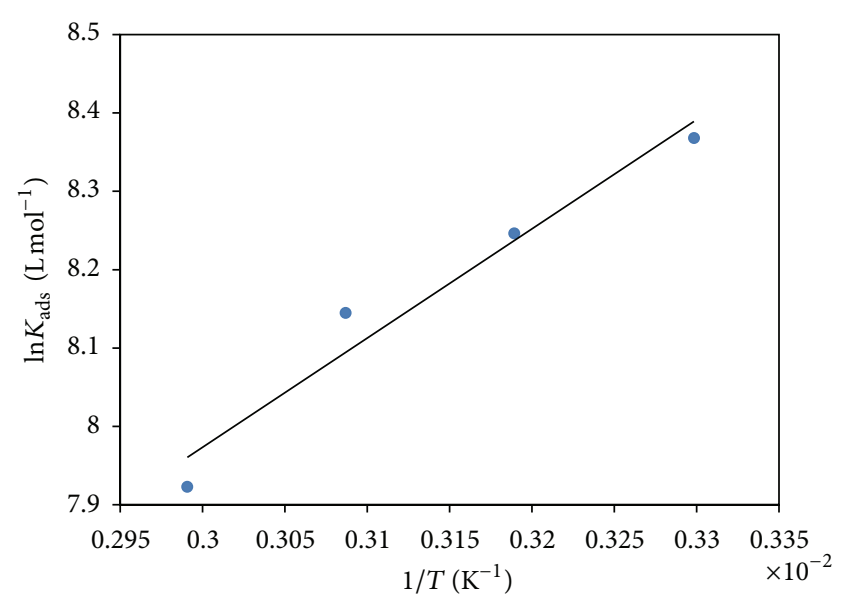

Figure 6: Plot of $\ln K_{\text {ads }}$ versus $1 / T$.

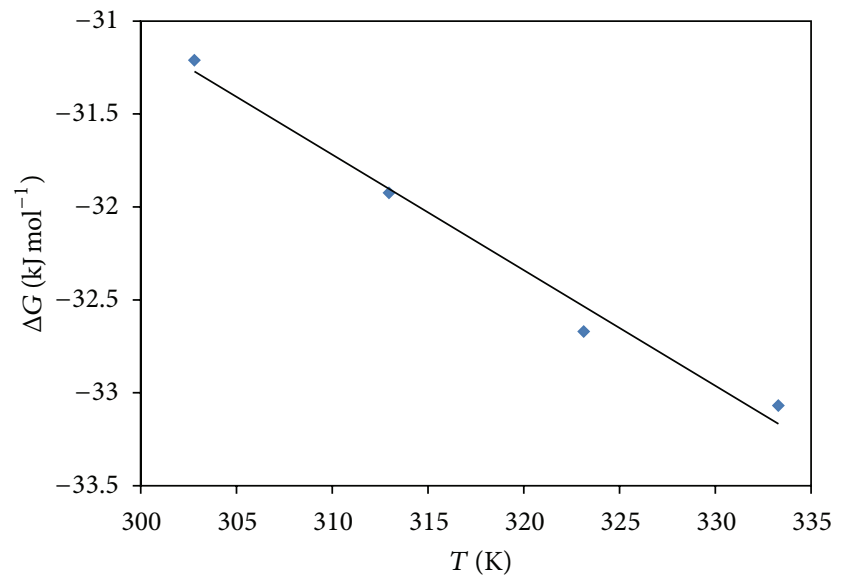

FIGURE 7: Plot of Gibbs free energy versus absolute temperature. 
TABLE 4: $E_{\text {corr }}, I_{\text {corr }}, R_{\mathrm{ct}}$, and IE \% obtained from polarization and impedance measurements for mild steel in industrial water medium containing various concentrations of AA extracts at $30^{\circ} \mathrm{C}$.

\begin{tabular}{|c|c|c|c|c|c|c|c|}
\hline \multirow{2}{*}{$C(\mathrm{ppm})$} & \multicolumn{2}{|c|}{ EIS } & \multirow[b]{2}{*}{$E_{\text {corr }}(\mathrm{mV})$} & \multirow[b]{2}{*}{$I_{\text {corr }}\left(\mathrm{mA} \mathrm{cm}^{-2}\right)$} & \multicolumn{2}{|c|}{ Polarization } & \multirow[b]{2}{*}{ IE \% } \\
\hline & $R_{\mathrm{ct}}\left(\Omega \mathrm{cm}^{2}\right)$ & IE \% & & & $b_{a}\left(\mathrm{~mA} \mathrm{dec}^{-1}\right)$ & $b_{c}\left(\mathrm{~mA} \mathrm{dec}^{-1}\right)$ & \\
\hline 0 & 111.7 & & -0.785 & 0.00476 & 6.000 & 1.034 & \\
\hline 200 & 226.7 & 50.72 & -0.503 & 0.00250 & 10.585 & 2.301 & 47.57 \\
\hline 400 & 232.7 & 51.99 & -0.574 & 0.00270 & 12.216 & 3.715 & 52.29 \\
\hline 600 & 290.6 & 61.56 & -0.706 & 0.00199 & 10.174 & 1.380 & 58.29 \\
\hline 800 & 328.7 & 66.01 & -0.684 & 0.00156 & 9.978 & 1.763 & 67.23 \\
\hline 1000 & 412.0 & 72.88 & -0.653 & 0.00128 & 7.320 & 1.481 & 73.14 \\
\hline 1200 & 559.7 & 80.04 & -0.610 & 0.00089 & 8.949 & 2.423 & 81.23 \\
\hline
\end{tabular}

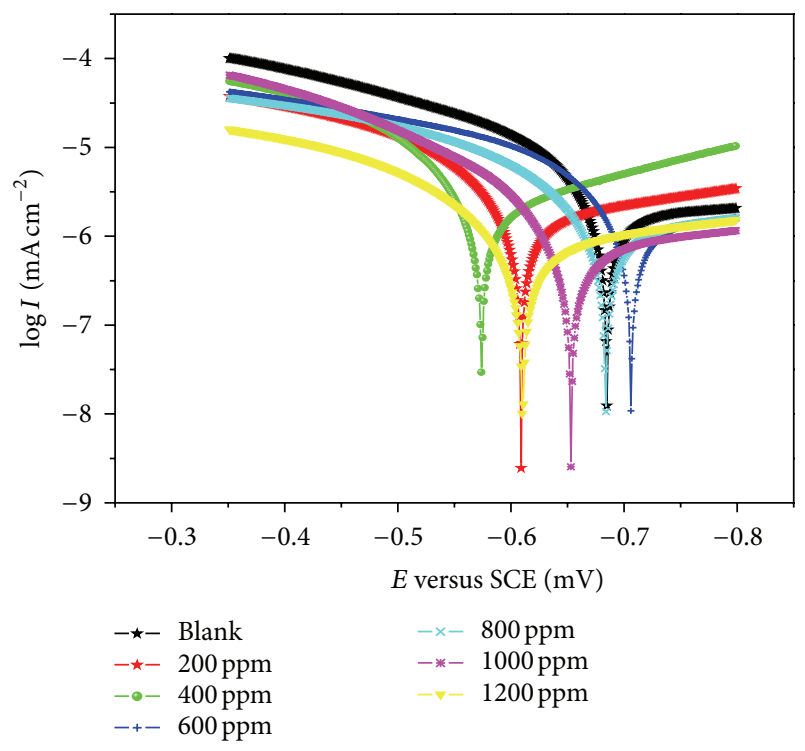

FIGURE 8: Potentiodynamic polarization curves for MS in industrial water medium containing different concentrations of compound AA extracts.

3.5. Potentiodynamic Polarization Studies. Anodic and cathodic polarization curves for MS in industrial water medium without and with different concentrations of AA extracts are shown in Figure 8. It is observed that both cathodic and anodic curves show a lower current density in the presence of AA extracts than those recorded in the industrial water medium alone. The values of corrosion potential $\left(E_{\text {corr }}\right)$, corrosion current density $\left(I_{\text {corr }}\right)$, anodic Tafel slope $\left(b_{a}\right)$ and cathodic Tafel slope $\left(b_{c}\right)$, and percentage inhibition efficiency (IE \%) are presented in Table 4 . The \% IE was calculated from polarization measurements according to following equation:

$$
\operatorname{IE~}(\%)=\frac{\left(I_{\text {corr }}\right)_{a}-\left(I_{\text {corr }}\right)_{p}}{\left(I_{\text {corr }}\right)_{a}} \times 100,
$$

where $\left(I_{\text {corr }}\right)_{a}$ and $\left(I_{\text {corr }}\right)_{p}$ are the corrosion current densities $\left(\mathrm{mA} \mathrm{cm}^{-2}\right)$ in the absence and presence of the inhibitor, respectively. From Figure 8, it is evident that the addition of AA extracts shifts the corrosion potential $\left(E_{\text {corr }}\right)$ values significantly in cathodic direction. The presence of AA

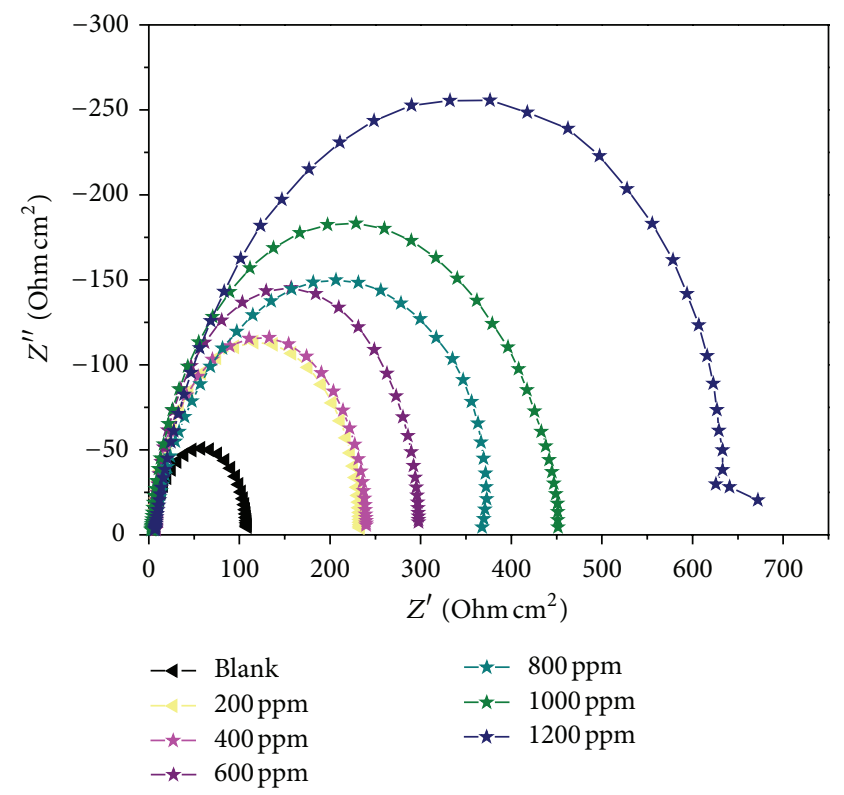

FIGURE 9: Nyquist plots for MS in industrial water medium containing different concentrations of AA extracts.

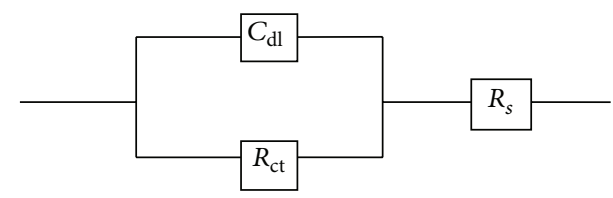

FIgURE 10: Equivalent circuit diagram.

extracts causes a significant decrease in the corrosion rate that is predominantly shifts the cathodic curves to lower values of current densities. On the other hand, the anodic reaction is slightly affected by AA extracts. But it alters both the tafel slope values indicating that AA extracts act as a mixed type of inhibitor [34]. The \% IE increases with the inhibitor concentration due to the increase in the blocked fraction of the electrode surface by adsorption. \% IE of AA extracts reaches to as high as 81.23 which indicates that AA extracts are a good inhibitor for MS in industrial water medium.

3.6. Electrochemical Impedance Spectroscopy (EIS). Figure 9 shows the impedance response of MS in industrial water 


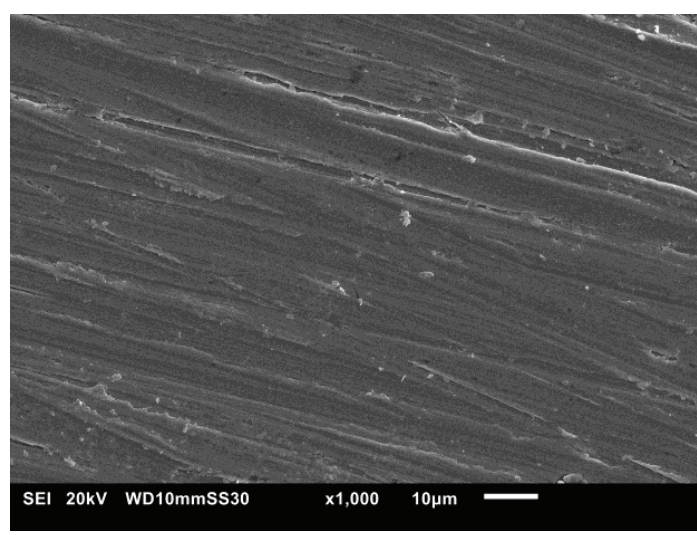

(a)

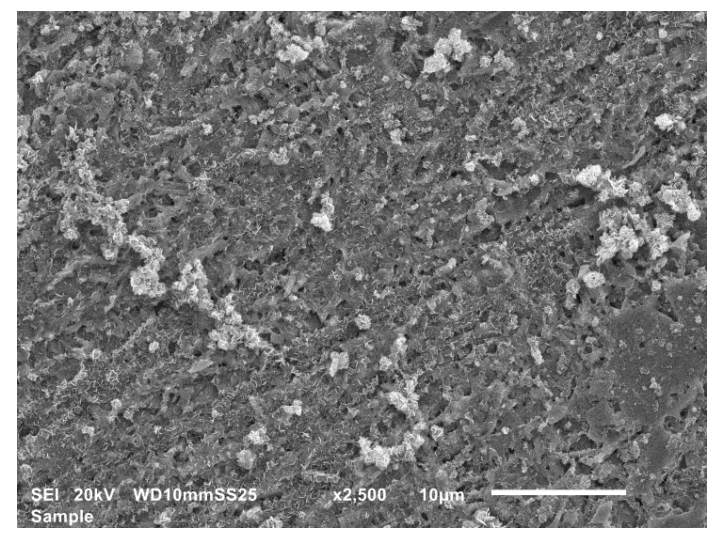

(b)

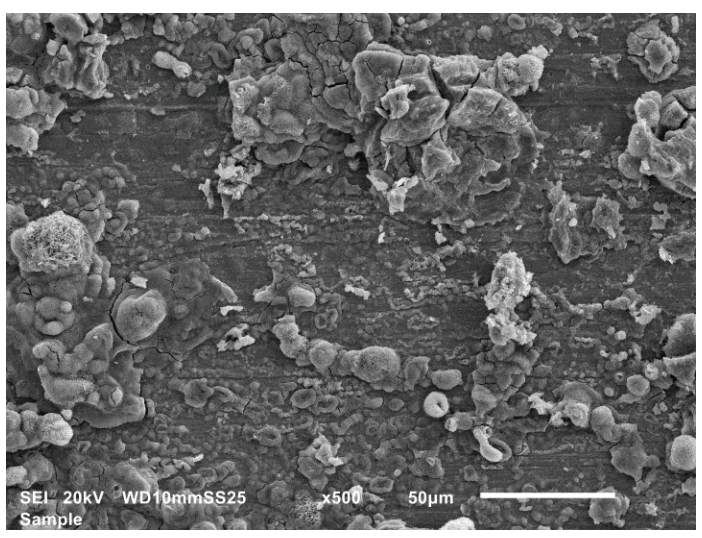

(c)

FIGURE 11: SEM images of MS in industrial water medium after $40 \mathrm{~h}$ of immersion at $30^{\circ} \mathrm{C}$ (a) before immersion (polished), (b) without inhibitor (blank), and (c) with 1200 ppm of AA extracts.

medium without and with different concentration of the inhibitor. Nyquist impedance plots were analyzed by fitting the experimental data to a simple circuit model (Figure 10). All the obtained plots show only one capacitive loop, and the diameter of the semicircle increases with increasing the inhibitor concentration suggesting that the inhibitive film formed was strengthened by the addition of inhibitor [35]. The presence of the inhibitor increases the impedance but does not change other aspects of the behavior. These results support the results of polarization measurements that the inhibitor does not alter the electrochemical reactions responsible for corrosion. The experimental results of EIS measurements for the corrosion of MS in industrial water medium in the absence and presence of AA extracts are given in Table 4 . Inspection of the Table 4 shows that AA extracts enhances the charge transfer resistance which is attributed to a decrease in local dielectric constant and/or an increase in the thickness of electrical double layer [36]. \% IE obtained from this technique is also comparable with those obtained from polarization measurements.

3.7. Scanning Electron Microscopy (SEM). To establish whether inhibition of MS surface is due to the formation of inhibitor protective film on the metal surface, SEM images were taken. SEM photographs obtained from MS surface after immersion in industrial water medium in the absence and presence of optimum concentration of inhibitors are shown in Figures 11(a)-11(c). Figure 11(a) shows the clear smooth surface morphology of MS examined. It can be seen from Figure 11(b) that the MS surface is strongly damaged in the absence of the inhibitor (blank). Figure 11(c) showed the protected MS surface after the addition of AA extracts, whereby the surface damage has diminished in comparison to the blank material. This is attributed to the formation of a good protective film on the MS surface.

\section{Conclusion}

(1) The inhibition efficiency of AA extracts increases with the inhibitor concentration and reaches a maximum at 1200 ppm of AA extracts.

(2) IE \% decreases with the increasing temperature in industrial water medium and remains constant at higher temperature.

(3) The adsorption of AA extracts in industrial water medium on MS surface obeys Langmuir adsorption isotherm. The adsorption process involved is both physisorption and chemisorption. 
(4) Polarization curves indicate that AA extracts act as mixed type of inhibitor.

(5) The adsorbed film containing the investigated compound was identified by SEM analysis.

\section{Acknowledgments}

The authors would like to thank University of Mysore, Mysore, MHRD and UGC, New Delhi, India, for providing financial assistance through Institution of Excellence (IOE) scheme. The authors are also thankful to Dr. Muralidhar and Mr. Yogeesh K. K., Department of Chemistry, K. S. Institute of Technology, Bangalore, India, for their help to carry out electrochemical work.

\section{References}

[1] E. Fouda, A. A. Sarawy, and E. E. Katori, "Thiazole derivatives as corrosion inhibitors for C-steel in sulphuric acid solution," European Journal of Chemistry, vol. 1, no. 4, pp. 312-318, 2010.

[2] A. S. Fouda, M. Diab, A. El-Sonbati, and S. A. Hassan, "Benzothiazole derivatives as corrosion inhibitors for carbon steel in $1 \mathrm{M}$ phosphoric acid $\left(\mathrm{H}_{3} \mathrm{PO}_{4}\right)$ solutions," African Journal of Pure and Applied Chemistry, vol. 7, no. 2, pp. 67-78, 2013.

[3] O. O. Xomet, N. V. Likhanova, N. Nava et al., "Thiadiazoles as corrosion inhibitors for carbon steel in $\mathrm{H}_{2} \mathrm{SO}_{4}$ solutions," International Journal of Electrochemical Science, vol. 8, pp. 735752, 2013.

[4] R. Bostan, S. Varvara, L. Gaina, and L. M. Mures, "Evaluation of some phenothiazine derivatives as corrosion inhibitors for bronze in weakly acidic solution," Corrosion Science, vol. 63, pp. 275-286, 2012.

[5] Z. Chen, L. Huang G, Zhang, Y. Qiu, and X. Guo, "Benzotriazole as a volatile corrosion inhibitor during the early stage of copper corrosion under adsorbed thin electrolyte layers," Corrosion Science, vol. 65, pp. 214-222, 2012.

[6] O. K. Abiola, J. O. E. Otaigbe, and O. J. Kio, "Gossipium hirsutum L. extracts as green corrosion inhibitor for aluminum in $\mathrm{NaOH}$ solution," Corrosion Science, vol. 51, no. 8, pp. 18791881, 2009.

[7] S. Deng and X. Li, "Inhibition by Jasminum nudiflorum Lindl. leaves extract of the corrosion of aluminium in $\mathrm{HCl}$ solution," Corrosion Science, vol. 64, pp. 253-262, 2012.

[8] S. Deng and X. Li, "Inhibition by Ginkgo leaves extract of the corrosion of steel in $\mathrm{HCl}$ and $\mathrm{H}_{2} \mathrm{SO}_{4}$ solutions," Corrosion Science, vol. 55, pp. 407-415, 2012.

[9] X. Li and S. Deng, "Inhibition effect of Dendrocalamus brandisii leaves extract on aluminum in $\mathrm{HCl}, \mathrm{H}_{3} \mathrm{PO}_{4}$ solutions," Corrosion Science, vol. 65, pp. 299-308, 2012.

[10] B. A. Abd-El-Nabey, A. M. A. Gaber, M. E. S. Ali, E. Khamis, and El- Housseiny, "Cannabis plant extract as inhibitor for the corrosion of nickel in $0.5 \mathrm{M} \mathrm{H}_{2} \mathrm{SO}_{4}$," International Journal Electrochemical Science, vol. 7, no. 12, pp. 11811-11826, 2012.

[11] S. S. Shivakumar and K. N. Mohana, "Centella asiatica extracts as green corrosion inhibitor for mild steel in $0.5 \mathrm{M}$ sulphuric acid medium," Advances in Applied Science Research, vol. 3, no. 5, pp. 3097-3106, 2012.

[12] S. S. Shivakumar and K. N. Mohana, "Studies on the inhibitive performance of Ccnnamomum zeylanicum extracts on the corrosion of mild Steel in hydrochloric acid and sulphuric acid medium," Journal of Materials and Environmental Science, vol. 4, pp. 448-459, 2013.

[13] S. S. Shivakumar and K. N. Mohana, "Ziziphus mauritiana leaves extracts as corrosion inhibitor for mild steel in $\mathrm{H}_{2} \mathrm{SO}_{4}$ and $\mathrm{HCl}$ solutions," European Journal of Chemistry, vol. 3, no. 4, pp. 426-432, 2012.

[14] I. B. Obot and N. O. Obi-Egbedi, "Ipomoea involcrata as an ecofriendly inhibitor for aluminium in alkaline medium," Portugaliae Electrochimica Acta, vol. 27, no. 4, pp. 517-524, 2009.

[15] A. Y. El-Etre, M. Abdallah, and Z. E. El-Tantawy, "Corrosion inhibition of some metals using lawsonia extract," Corrosion Science, vol. 47, no. 2, pp. 385-395, 2005.

[16] M. A. Alam, N. Slahin, R. Uddin et al., "Analgesic and neuropharmacological investigations of the aerial part of Achyranthes aspera Linn," Stamford Journal of Pharmaceutical Sciences, vol. 1, no. 1, pp. 44-50, 2008.

[17] R. D. Rameshwar and N. Akito, "Three oleanoliic acid glycosides from medicinally important seeds of Achyranthes aspera," Natural Product Communications, vol. 2, pp. 727-730, 2007.

[18] H. N. Khastgir, S. K. S. Gupta, and P. S. Gupta, "The sapogenin from seeds of Achyranthes aspera Linn," Journal of the Indian Chemical Society, vol. 35, pp. 693-694, 1958.

[19] A. Banerji and M. S. Chadha, "Insect moulting hormone from Achyranthes aspera," Phytochemistry, vol. 9, no. 7, p. 1671, 1970.

[20] G. Michl, D. Abebe, F. Bucar et al., "New triterpenoid saponins from Achyranthes aspera Linn," Helvetica Chimica Acta, vol. 83, no. 2, pp. 359-363, 2000.

[21] M. H. Hussin and M. J. Kassim, "The corrosion inhibition and adsorption behavior of Uncaria gambir extract on mild steel in $1 \mathrm{M} \mathrm{HCl}, "$ Materials Chemistry and Physics, vol. 125, no. 3, pp. 461-468, 2011.

[22] S. S. Shivakumar, K. N. Mohana, and D. M. Gurudatt, "Inhibition performance and adsorption behavior of spinacia oleracea leaves extracts on mild steel corrosion in hydrochloric acid Medium," Chemical Science Transactions, vol. 2, no. 1, pp. 163175, 2013.

[23] M. Schorr and J. Yahalom, "The significance of the energy of activation for the dissolution reaction of metal in acids," Corrosion Science, vol. 12, no. 11, pp. 867-868, 1972.

[24] O. K. Abiola and A. O. James, "The effects of Aloe vera extract on corrosion and kinetics of corrosion process of zinc in $\mathrm{HCl}$ solution," Corrosion Science, vol. 52, no. 2, pp. 661-664, 2010.

[25] H. Cang, Z. Fei, J. Shao, W. Shi, and Q. Xu, "Corrosion inhibition of mild steel by aloes extract in $\mathrm{HCl}$ solution medium," International Journal of Electrochemical Science, vol. 8, pp. 720734, 2013.

[26] M. Bouklah, B. Hammouti, M. Lagrenée, and F. Bentiss, "Thermodynamic properties of 2,5-bis(4-methoxyphenyl)1,3,4-oxadiazole as a corrosion inhibitor for mild steel in normal sulfuric acid medium," Corrosion Science, vol. 48, no. 9, pp. 2831-2842, 2006.

[27] G. N. Mu, X. Li, and F. Li, "Synergistic inhibition between ophenanthroline and chloride ion on cold rolled steel corrosion in phosphoric acid," Materials Chemistry and Physics, vol. 86, no. 1, pp. 59-68, 2004.

[28] S. A. Ali, M. T. Saeed, and S. U. Rahman, "The isoxazolidines: a new class of corrosion inhibitors of mild steel in acidic medium," Corrosion Science, vol. 45, no. 2, pp. 253-266, 2003.

[29] M. Scendo, "The effect of purine on the corrosion of copper in chloride solutions," Corrosion Science, vol. 49, no. 2, pp. 373390, 2007. 
[30] M. Hosseini, S. F. L. Mertens, and M. R. Arshadi, "Synergism and antagonism in mild steel corrosion inhibition by sodium dodecylbenzenesulphonate and hexamethylenetetramine," Corrosion Science, vol. 45, no. 7, pp. 1473-1489, 2003.

[31] I. Ahamad, R. Prasad, and M. A. Quraishi, "Inhibition of mild steel corrosion in acid solution by Pheniramine drug: Experimental and theoretical study," Corrosion Science, vol. 52, no. 9, pp. 3033-3041, 2010.

[32] X. Li and G. Mu, "Tween-40 as corrosion inhibitor for cold rolled steel in sulphuric acid: weight loss study, electrochemical characterization, and AFM," Applied Surface Science, vol. 252, no. 5, pp. 1254-1265, 2005.

[33] O. Benali, L. Larabi, M. Traisnel, L. Gengembre, and Y. Harek, "Electrochemical, theoretical and XPS studies of 2-mercapto1-methylimidazole adsorption on carbon steel in $1 \mathrm{M} \mathrm{HClO}_{4}$," Applied Surface Science, vol. 253, no. 14, pp. 6130-6139, 2007.

[34] P. B. Raja and M. G. Sethuraman, "Inhibitive effect of black pepper extract on the sulphuric acid corrosion of mild steel," Materials Letters, vol. 62, no. 17-18, pp. 2977-2979, 2008.

[35] H. Amar, T. Braisaz, D. Villemin, and B. Moreau, "Thiomorpholin-4-ylmethyl-phosphonic acid and morpholin4-methyl-phosphonic acid as corrosion inhibitors for carbon steel in natural seawater," Materials Chemistry and Physics, vol. 110, no. 1, pp. 1-6, 2008.

[36] M. A. Quraishi, A. Singh, V. K. Singh, D. K. Yadav, and A. K. Singh, "Green approach to corrosion inhibition of mild steel in hydrochloric acid and sulphuric acid solutions by the extract of Murraya koenigii leaves," Materials Chemistry and Physics, vol. 122, no. 1, pp. 114-122, 2010. 

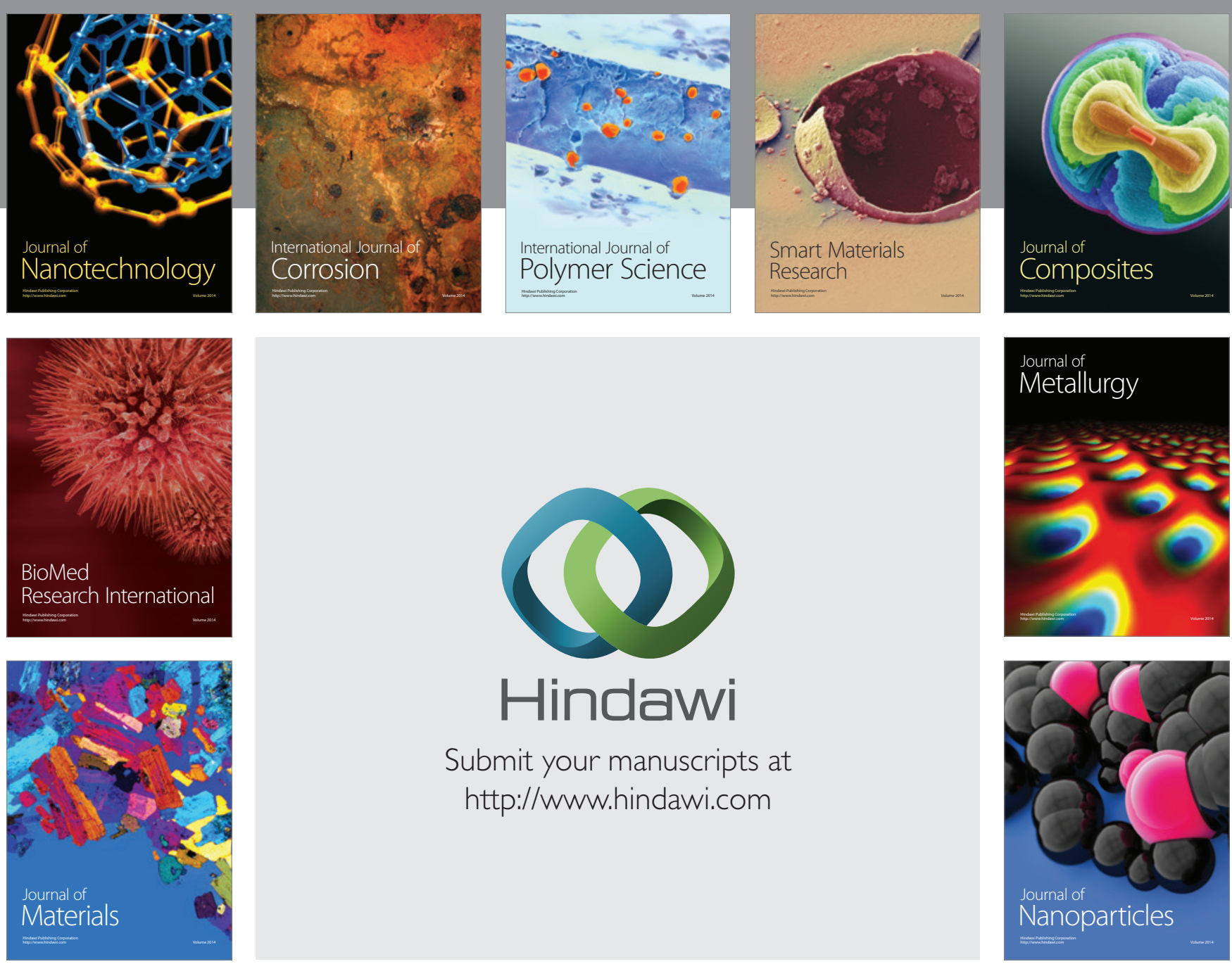

Submit your manuscripts at http://www.hindawi.com
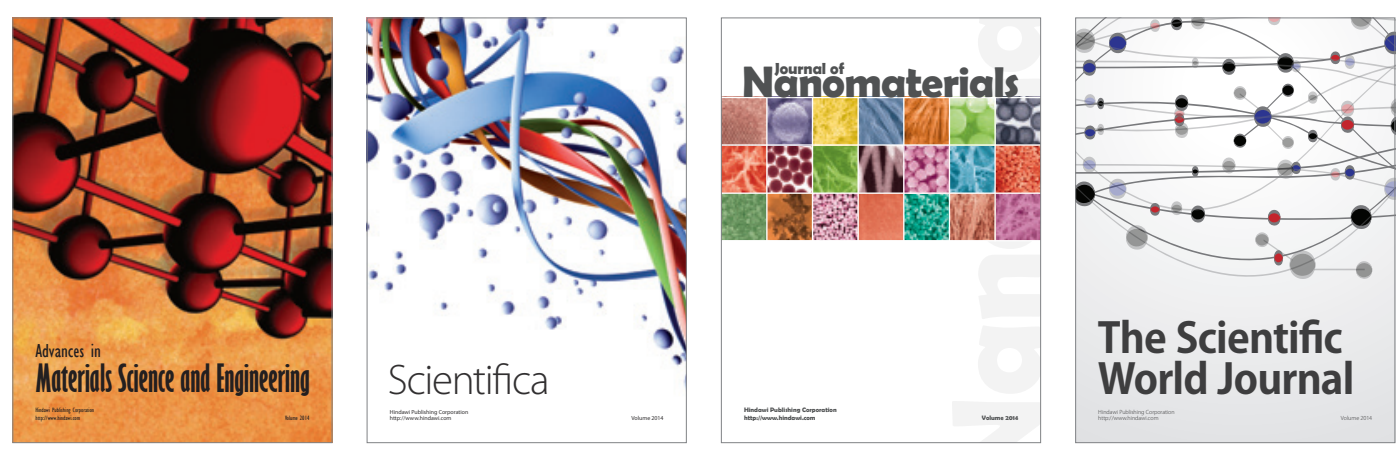

\section{The Scientific World Journal}
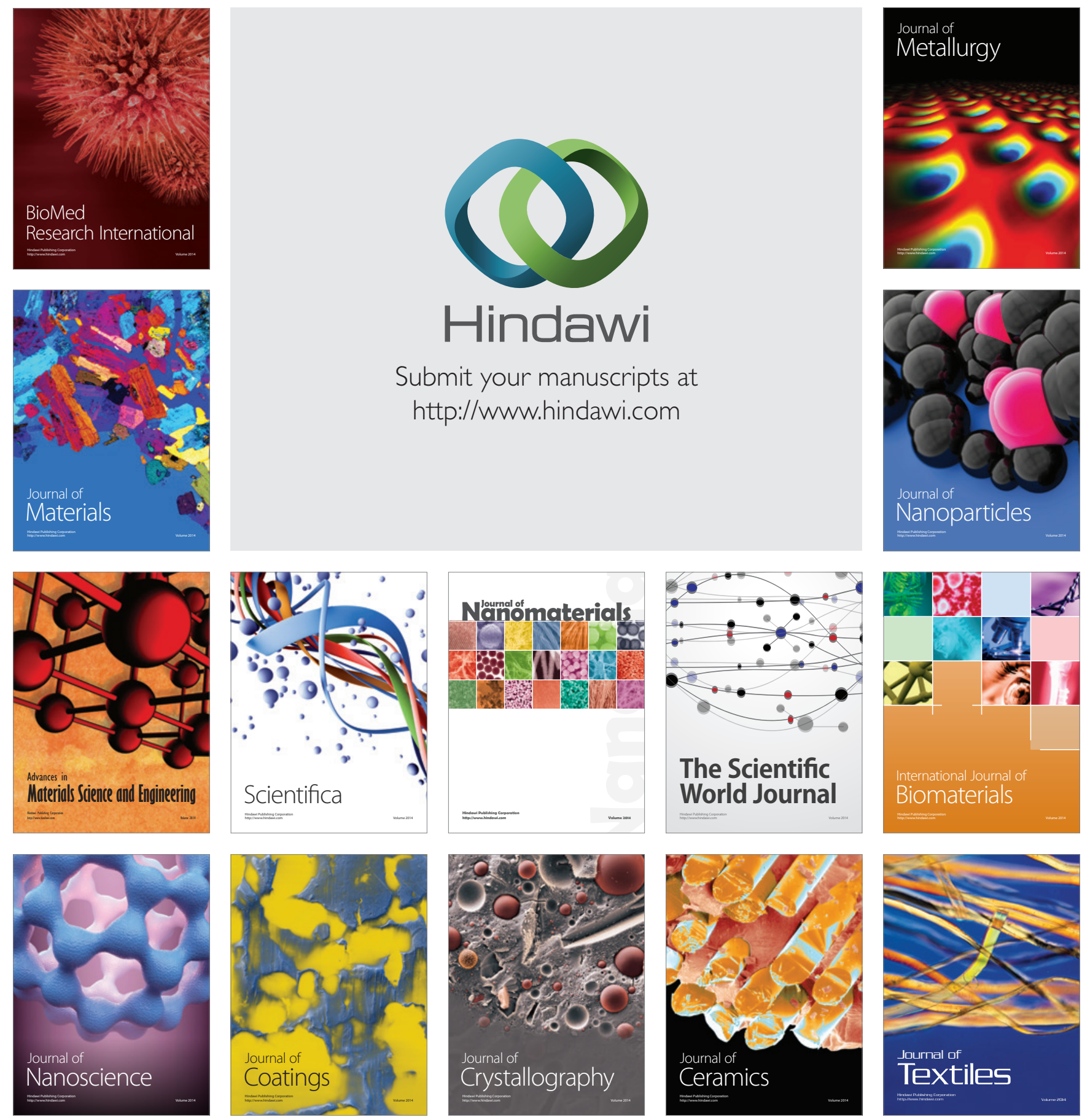